\title{
EDUCAÇÃO SUPERIOR E MOBILIDADE NAS FAIXAS DE FRONTEIRA: ALGUNS EFEITOS DA POLÍTICA EM CURSO
}

\author{
Adriana de Lurdes Trentin ALVARES ${ }^{1}$ \\ Giselle Cristina Martins REAL ${ }^{2}$
}

RESUMO: A educação superior tornou-se elemento estratégico para aceleração dos processos de desenvolvimento e consolidação das economias nas últimas décadas, promovendo sua expansão, especialmente na esfera privada. No entanto, não tem sido suficiente para absorver a demanda, em ascensão, de algumas carreiras mais atrativas. Esse processo tem estimulado estudantes brasileiros a buscarem instituições de educação superior em países fronteiriços, como Paraguai e Bolívia, gerando preocupações com a qualidade e equivalência curricular desses cursos. Os estudos sobre a temática são incipientes, especialmente considerando os efeitos da mobilidade nos currículos de cursos de graduação nestes espaços. Justifica-se a temática, tendo em vista as tendências e tensões acerca da globalização e internacionalização da educação superior, com vistas a viabilizar novos estudos sobre esse movimento que se apresenta de forma crescente. Adotou-se como metodologia a análise documental e bibliográfica. Além disso, espera-se que o estudo contribua para o desvelamento de possíveis efeitos da privatização da educação superior nas regiões de fronteira com o Brasil, de forma a indicar a realização de estudos, para que se encontrem alternativas de políticas que permitam o monitoramento da qualidade na educação superior para além dos sistemas de avaliação e regulação vigentes.

PALAVRAS-CHAVE: Educação superior. Políticas de avaliação. Mobilidade. Educação transfronteira.

\section{Introdução}

A transição para o século XXI, longe de ser apenas um marco cronológico, tem sido marcado por profundas mudanças na humanidade na natureza e nas relações delas emanadas. A educação de maneira geral e a educação superior, objeto deste estudo, encontram-se imbricadas nesse processo. Assim, para entendermos as políticas da educação superior nas sociedades atuais, é importante observarmos como ela está relacionada às mudanças impostas pelo processo de globalização econômico que

\footnotetext{
${ }^{1}$ Mestranda em Educação. UFGD - Universidade Federal da Grande Dourados. Dourados - MS - Brasil. 79825-070 - adritren@ hotmail.com.

${ }^{2}$ Doutora em Educação. USP - Universidade de São Paulo. Professor Adjunto, atuando na graduação e na pós-graduação stricto sensu. UFGD - Universidade Federal da Grande Dourados. Dourados - MS Brasil.79825-070 - gisellereal@ufgd.edu.br.
} 
circunda o mundo contemporâneo, provocando mudanças no cenário internacional e nacional.

Neste sentido, a relação indissociável entre o processo de produção e o de unificação da educação superior a nível local/internacional vem exigindo dos governos a implementação de reformas nesta área (FERREIRA; OLIVEIRA, 2010), pois a mesma é vista como elemento dinamizador e estratégico para a aceleração dos processos de desenvolvimento e consolidação das economias (DIAS SOBRINHO, 2003).

Partindo dessa premissa, o de redimensionar as políticas para a educação, em especial a educação superior, esse trabalho analisa possíveis efeitos do processo de expansão e regulação deste nível de ensino no contexto dos espaços fronteiriços com o Brasil.

Afinal, não se pode negar que as mudanças ocorridas no contexto socioeconômico, cultural e tecnológico têm gerado novas necessidades formativas, levando as pessoas a possuírem níveis mais elevados de educação para poderem atuar no mundo globalizado (CASTRO; NETO, 2012). Para Carneiro e Novaes (2009) isso representa dizer que do ponto de vista econômico, as exigências de competitividade e produtividade passaram a imprimir um novo patamar de qualificação profissional. Esse cenário exige que os trabalhadores tenham um domínio especializado para poder lidar com situações complexas, especialmente aquelas advindas do emprego das tecnologias digitais.

Diante desse cenário, a educação superior, em articulação com as atuais tendências, vem sendo concebida como forma de viabilizar: competitividade ao contribuir para pesquisas de novas tecnologias, atratividade de estudantes com potencial criativo, mobilidade de estudantes e professores para a disseminação de conhecimento, bem como o aumento da capacidade de empregabilidade (ROBERTSON, 2009; ERICHSEN, 2007; HORTALE; MORA, 2004).

Cumpre destacar que essas características atribuídas à educação superior e ao seu processo de expansão assumem papel de destaque na política educacional brasileira. Desse modo, o Brasil, buscando se ajustar às novas demandas da economia mundial instituiu reformas em seu sistema educacional, promovendo desde a década de 1990 uma completa reestruturação no seu sistema de ensino, universalizando o acesso e adotando sistemas de avaliação externa. A educação superior também passou por reformas, objetivando a sua expansão com qualidade (GOMES; MORAES, 2009; 
SOUZA, 2005) e as diretrizes e bases que sustentavam o modelo legal vigente sofreram reestruturações, gerando mudanças significativas nos padrões de avaliação e regulação (DOURADO; OLIVEIRA; CATANI, 2003; CATANI; OLIVEIRA, 2002).

Diante deste cenário, tendo em vista as tendências e tensões acerca da globalização e da internacionalização, questiona-se: o que a literatura educacional traz sobre a educação superior nas faixas de fronteira do Brasil com países vizinhos?

Assim, o objetivo deste trabalho é socializar reflexões a partir de análise bibliográfica sobre a educação superior nesses espaços, com vistas a subsidiar novos e mais estudos sobre esse movimento que vem se apresentando de forma crescente. Especialmente quando se observa que os estudos sobre a temática são incipientes, sobretudo considerando os efeitos da mobilidade nos currículos de cursos de graduação nesta área (DIAS SOBRINHO, 2003). Para tanto, adotou-se como metodologia a pesquisa qualitativa, a partir de análise documental e bibliográfica, com apresentação do processo de mobilidade nas faixas de fronteira e algumas políticas que engendram a avaliação e regulação da educação superior em contextos fronteiriços.

\section{Mobilidade nas faixas de fronteira: a demanda por educação superior}

O governo brasileiro tem instituído uma política de expansão nas instituições superiores nos últimos anos, procurando atender a demanda interna (OLIVEIRA, 2006). No entanto, a oferta de vagas para determinados cursos é muito limitada, o que acaba contribuindo para o movimento de estudantes brasileiros em procurar instituições de educação superior estrangeiras para desenvolverem seus estudos de graduação, especialmente em países fronteiriços, como Bolívia e Paraguai, e que ao retornarem ao Brasil necessitam da revalidação de seus títulos (CONCEIÇÃO, 2013).

Esse movimento de circulação de pessoas, projetos, programas, conhecimentos, currículos, enfim ideias em espaços de fronteira é um fenômeno mundial e crescente especialmente considerando as questões comerciais que pode envolvê-lo (KNIGHT, 2006). Segundo a autora:

A mobilidade de estudantes, professores, conhecimentos e valores tem sido parte da educação superior por séculos, mas somente nas duas últimas tem tido um significativo crescimento na mobilidade de programas e serviços físicos e virtuais. Isto apresenta novas oportunidades - para o aumento do acesso à educação superior, para alianças estratégicas entre países e regiões, para a produção e troca de novos conhecimentos, para o movimento de acadêmicos e 
profissionais, [...], para a melhoria da qualidade acadêmica. Mas assim como a lista de potenciais benefícios é longa e variada, assim é a lista de riscos potenciais. (KNIGHT, 2006, p.64, tradução livre).

No mesmo sentido, Dias Sobrinho (2003, p.15) alerta que:

Com efeito, na atualidade além desse fenômeno da internacionalização entendida como intercâmbio acadêmico solidário e não competitivo, cujo sentido principal está mais vinculado às iniciativas e programas de mobilidade estudantil e cooperação acadêmica, a globalização instaura outros processos e objetivos heterogêneos e ainda não muito bem delimitados, que impregnam de motivações econômicas as práticas educativas.

Portanto, o que se observa, no caso dos espaços fronteiriços com o Brasil, é que o processo de mobilidade que vem se efetivando têm características distintas daquelas apresentadas pelos estudos internacionais que tratam da "educação transfronteira" ou "educação sem fronteira", termos explicitados e cunhados por KNIGHT (2006) e interpretados e traduzidos por Dias Sobrinho (2003), no Brasil.

Estudos de Varghese (2008) apontam que os principais motivos que levam a mobilidade estudantil são: custo da educação, afinidade ideológica, proficiência na língua, superioridade acadêmica reconhecida das instituições nos países de acolhimento, interesse na aquisição da língua estrangeira, aumento das oportunidades de emprego, crescentes níveis de renda nos países de origem e facilidades nas formalidades burocráticas.

Nesse sentido, pode-se observar que a mobilidade de estudantes brasileiros para países como Paraguai e Bolívia não é justificada pelas mesmas razões que ocorrem no contexto internacional, uma vez que as instituições acolhedoras não têm o reconhecimento acadêmico que explicassem o movimento migratório, explicitando razões mais focadas pelas questões de fundo econômico (REAL, 2009, 2010).

Essa ótica de educação como mercadoria vem sendo influenciada pelo mercado, causando um barateamento da educação superior, e despertando o interesse de estudantes brasileiros, que se lançam a procura por cursos em Universidades de outros países na tentativa de obter um título de nível superior com preço abaixo do mercado brasileiro. Especialmente considerando a valorização da moeda brasileira, o real, à moeda desses países (REAL, 2011).

Assim, a "educação transfronteira" que ocorre nos espaços vizinhos ao Brasil, apresenta impactos não esperados, ainda com vieses negativos, que envolvem 
complexidades, relacionadas as econômicas, mas também, técnico-formais e políticas. Um desses aspectos, relacionado às questões técnico-formais é a passagem migratória de estudantes brasileiros para países fronteiriços, que posteriormente têm dificuldades para a revalidação de seus títulos, em virtude da falta de acordos que já vem sendo sentido (CONCEIÇÃO; REAL, 2009).

Verifica-se nos dados da UNESCO (2009) que os cinco destinos preferidos dos brasileiros para mobilidade de graduação são: EUA, França, Portugal, Alemanha e Reino Unido. Nos dados referentes a 2011, houve apenas a substituição do quinto destino que passa a ser Espanha e não mais Reino Unido (OLIVEIRA, 2014). Com isso, observa-se que não há registros oficiais que explicitem a preferência de brasileiros para mobilidade com os países vizinhos que inclusive participam do bloco Mercosul ${ }^{3}$.

Por outro lado, se comparar os dados da UNESCO (2009) com os de UNESCO (2011), observa-se que o Brasil avançou como destino de procura por estudantes estrangeiros, originários dos países do bloco Mercosul, como: Argentina, Paraguai e Uruguai. Até o ano de 2009 o Brasil não figurava em nenhum dos cinco destinos preferidos por estudantes destes países. A partir de 2011, o Brasil passa a ser o $4^{\circ}$ destino dos estudantes argentinos, o $2^{\circ}$ de estudantes paraguaios e o $5^{\circ}$ dos estudantes uruguaios (OLIVEIRA, 2014).

De forma geral, esses dados explicitam uma discrepância entre as políticas em curso e o movimento real migratório de estudantes brasileiros, que diante de sua complexidade sinalizam a presença de uma problemática que deve ser melhor analisada.

Real (2011) destaca que à medida que a oferta da educação superior, especialmente no caso brasileiro, não atende à demanda existente acaba gerando iniciativas dos próprios estudantes na busca por solucionar o acesso à educação superior e muitas vezes em outros países. Esse movimento pode ser explicitado pela proximidade fronteiriça entre os países e pelas maiores possibilidades de acesso às instituições estrangeiras, uma vez que não há processo seletivo (vestibular) e a moeda brasileira, o real, é mais valorizado que a moeda desses países, contribuindo para que a educação privada se torne mais barata para os brasileiros (REAL, 2009).

Importante destacar que o curso de Medicina tem sido um dos mais procurados pelos estudantes quando buscam os países fronteiriços para estudar. E apesar do

${ }^{3}$ Criado em março de 1991 como projeto político de internacionalização das economias e fortalecimento das relações regionais e internacionais. São países membros do Mercosul: Argentina, Brasil, Paraguai, Uruguai. Estados associados: Bolívia, Chile Colômbia, Equador, Peru e Venezuela. E o México está como Estado observador. 
aumento no número de vagas para o curso no Brasil nos últimos anos, a oferta não tem sido suficiente para atender à demanda.

Esse movimento por obtenção de títulos no âmbito dos países do Mercosul para posterior revalidação no Brasil constitui-se um efeito não esperado da política de expansão da educação superior, especialmente quando há risco de não reconhecimento desses títulos. Segundo Lamarra (2004), esses entraves seriam de pontos incongruentes como: currículo diferenciado, políticas de avaliações distintas, normas jurídico-legais particularizadas, entre outros.

Mesmo assim, esses fatores não têm inviabilizado a migração e sim gerado embates nos processos de revalidação dos títulos de educação superior, principalmente nos de Medicina, devido à crescente expansão do mercado nesse setor (OLIVEIRA, 2009; SGUISSARDI, 2008). Isto é percebido nas decisões tomadas no setor educacional do Mercosul, onde mecanismos de avaliação e acreditação são elaborados, como forma de subsidiar a construção de um padrão de qualidade comum à educação superior nesses países, a saber, o MEXA ${ }^{4}$, no período de 2003 a 2006 e posteriormente o ARCU-SUL ${ }^{5}$.

No entanto, este movimento tem levado o governo brasileiro a adotar medidas, através de políticas específicas, para além das normas regulamentares previstas na legislação educacional, a fim de viabilizar o acesso a carreira com garantia de qualidade.

\section{Conformação curricular: o programa revalida para o curso de medicina}

As transformações ocasionadas pelo processo de globalização e que tem alterado de forma significava grande parte das atividades humanas, chegaram à educação superior estabelecendo novas posturas. Tanto as estruturas do ensino, quanto o contexto em que ele se configura, têm passado por transformações importantes, estimulados por questões, como: avanço dos serviços de comunicação e tecnologia, ampliação da mobilidade de mão de obra, maior ênfase na economia de mercado e na liberalização do comércio, maior enfoque na chamada "sociedade do conhecimento", maior

\footnotetext{
${ }^{4}$ Mecanismo Experimental de Avaliação: com o propósito de promover o reconhecimento recíproco de títulos de graduação universitária nos países participantes (BRASIL, 2009).

${ }^{5}$ Criado por meio da Decisão no $17 / 08$, do Conselho Mercado Comum - CMC. O Sistema ARCU-SUL visa estabelecer e assegurar critérios regionais de qualidade de cursos de graduação para a melhoria permanente da formação em nível superior, necessária para a promoção do desenvolvimento educacional, econômico, social, político e cultural dos países da região (BRASIL, 2011a).
} 
investimento no setor privado em contraposição à queda de investimento no setor público (KNIGHT, 2005).

Neste sentido, a internacionalização da educação a partir do processo de globalização e a constituição dos blocos supranacionais vêm promovendo a construção de políticas de fomento à mobilidade estudantil e de professores nesse setor, a exemplo do que ocorre com o Processo de Bolonha ${ }^{6}$ (HORTALE; MORA, 2004; ROBERTSON, 2009; PEREIRA, 2011). Essa mobilidade por sua vez, apresenta algumas complexidades ao processo de revalidação, na medida em que tem demandado alterações na legislação vigente.

Um ponto que merece destaque na crescente preocupação da expansão da educação superior pode ser observado na recente estruturação do processo de revalidação de títulos (BRASIL, 2005) obtidos por brasileiros no exterior, especialmente considerando o espaço do Mercosul.

Preocupação que já aparecia na LDB no art. $48 \S 2^{\circ}$, estabelecendo que os diplomas de graduação expedidos por universidades estrangeiras seriam revalidados por universidades públicas que tivessem curso do mesmo nível e área ou equivalentes (BRASIL, 1996).

Assim, segundo informações que constam no sítio do Ministério da Educação, para ter validade nacional, o diploma de graduação tem que ser revalidado por universidade pública brasileira e que tenha curso igual ou similar, reconhecido pelo governo federal, conforme a Resolução do Conselho Nacional de Educação (CNE/CES) $\mathrm{n}^{\circ} 8$, de 04 de outubro de 2007 (BRASIL, 2007).

Cumpre destacar que o Brasil ainda não possui nenhum acordo de reconhecimento automático de diplomas ${ }^{7}$ (AGÊNCIA BRASIL, 2014), portanto as regras supracitadas são aplicadas a diplomas de cursos de graduação obtidos no exterior, ressaltando-se que as mesmas não se aplicam para o curso de Medicina, haja vista é o

${ }^{6}$ Criado em junho de 1999. A Declaração de Bolonha marca uma mudança em relação às políticas ligadas ao ensino superior dos países envolvidos estabelecendo em comum um Espaço Europeu de Ensino Superior a partir do comprometimento dos países signatários em promover reformas de seus sistemas de ensino.

${ }^{7}$ A Comissão de Educação, Cultura e Esporte do Senado aprovou a proposta que simplifica a revalidação de diplomas de cursos presenciais de graduação, mestrado e doutorado, expedidos por instituições de educação superior estrangeiras cuja excelência seja atestada e declarada pelo Poder Público brasileiro, Com a aprovação, diplomas de universidades estrangeiras, cuja excelência seja atestada e declarada pelo órgão responsável pela coordenação da política nacional de educação, não precisarão ser analisados individualmente por uma comissão, como acontece atualmente. Para auxiliar essa análise o poder público divulgará anualmente relação de cursos, instituições e programas de ensino estrangeiros de excelência, acompanhada de instrução de procedimentos e orientações para a tramitação célere dos processos de revalidação. 
curso mais procurado pelos jovens que almejam uma carreira de sucesso numa prática que possa trazer-lhes prestígio e retorno financeiro significativo (SCOTT, 2008). Para tanto, o MEC instituiu normas específicas para essa categoria a fim de observar se existe uma correlação entre as normas estipuladas no Brasil, com as normas dos países oriundos do diploma do candidato.

Para isso implementou o Programa Revalida, através da Portaria Interministerial $\mathrm{n}^{\mathrm{o}} 278 / 11$, onde "[...] disponibiliza exame de avaliação com base em matriz referencial de correspondência curricular, com a finalidade de subsidiar os procedimentos de revalidação conduzidos por universidades públicas." (BRASIL, 2011b). Este programa tem o propósito de revalidar diplomas médicos expedidos por instituição de educação superior estrangeira, no Brasil.

O mesmo se configura numa nova sistemática de revalidação de diplomas de médicos brasileiros, pois até recentemente as medidas eram focadas nas próprias universidades. O MEC, por meio do Instituto Nacional de Estudos e Pesquisas Educacionais (INEP), tem elaborado e aplicado provas e exames, destinadas ao processo de revalidação, cabendo às universidades federais o processo de inscrição e de encaminhamento ao órgão central (CONCEIÇÃO, 2011).

O exame é baseado na Matriz Referencial de Correspondência Curricular e serve para verificar a aquisição de conhecimentos, habilidades e competências requeridas para o exercício profissional adequado aos princípios e necessidades do SUS. A realização do exame assim, nomeada a avaliação dos candidatos, acontece em duas avaliações sucessivas e eliminatórias (CONCEIÇÃO, 2011).

No entanto, tendo em vista as iniciativas governamentais para facilitar a revalidação de diplomas por meio de projetos e exames próprios, ainda encontram-se embates e tensões no processo. De acordo com dados levantados por Conceição $(2013)^{8}$ nas últimas edições do Revalida, menos de $10 \%$ dos candidatos participantes foram aprovados, o que poderia apontar para a falta de uma concepção de qualidade na formação de médicos, particularmente no contexto dos países que compõem o Mercosul, pois a maior parte dos egressos inscritos vem de instituições da Bolívia e Paraguai.

Desse modo, algumas indagações surgiram a partir desses resultados, ocasionando dúvidas acerca das (as)simetrias entre a Matriz Referencial para o Curso de

\footnotetext{
${ }^{8}$ Na edição de 2010 houveram 507 candidatos inscritos e somente 02 aprovações, no ano de 2011 houve 677 candidatos com 65 aprovações e em 2012, 922 candidatos se inscreveram havendo 77 aprovações.
} 
Medicina proposto pelas instituições de educação superior bolivianas e paraguaias em relação a Matriz Referencial brasileira. Logo, a implementação do Programa Revalida, poderia induzir as instituições de educação superior privadas da Bolívia e Paraguai a buscarem uma conformação curricular para o curso de Medicina, com vistas a manter o número de estudantes brasileiros que migram anualmente para esse país?

\section{Influência brasileira na conformação curricular regional em cursos de medicina}

A educação superior, no espaço latino-americano tem passado por transformações, a partir dos anos de 1990, para enfrentar os desafios decorrentes das transformações produtivas e dos avanços tecnológicos, considerando-se que o “[...] fator humano e a qualidade de sua formação constituem sólida garantia de êxito nos processos de integração" (MERCOSUL, 1991).

Desse modo, a expansão e a avaliação da educação superior passaram a constituir-se elementos centrais na política educacional dos países que compõe o Mercosul. Segundo Dias Sobrinho (2003), a avaliação educacional, no contexto contemporâneo, passa a se constituir em um pressuposto de qualidade na medida em que é capaz de mensurá-la.

Observa-se que a avaliação vem tomando formas de centralidade à medida que é implementada e testada. Assim, uma cultura de avaliação torna-se vital para os países frente a expansão dos níveis de escolaridade e as exigências ocasionadas com o decorrer das transformações globais.

É nesse sentido que o governo brasileiro tem adotado procedimentos próprios para a revalidação de diplomas de médicos, como o Revalida, que embora específico para a área médica, constituiu-se em dimensão educativa e pedagógica da política educacional, atribuindo a avaliação, por meio de exames estandardizados, potencial para qualificar o processo de revalidação desses títulos, haja vista a Medicina ser das mais atrativas carreiras para o mercado de trabalho, fato observado pela relação candidato/vagas nos vestibulares das instituições de educação superior. A Tabela 01 apresenta dados sobre o curso de Medicina e sua demanda no Brasil, considerando o período de 1995 a 2012. 
Tabela 1 - Demanda do curso de Medicina - Brasil - 1995/2012

\begin{tabular}{|c|c|c|c|c|}
\hline \multirow{2}{*}{ Ano } & \multicolumn{2}{|c|}{$\begin{array}{c}\mathrm{N}^{\circ} \text { de vagas ofertadas em cursos de } \\
\text { graduação }\end{array}$} & \multicolumn{2}{|c|}{$\mathbf{N}^{0}$ inscrições no vestibular } \\
\hline & Total geral & Medicina & Total geral & Medicina \\
\hline 1995 & 610.355 & 8.247 & 510.377 & 7.888 \\
\hline 2012 & 4.653 .814 & 17.931 & 11.957 .756 & 850.674 \\
\hline
\end{tabular}

Fonte: Elaboração própria com dados das Sinopses Estatísticas da Educação Superior Graduação/Inep, 1995/2012 (BRASIL, 1995).

A Tabela acima demonstra a demanda do curso de Medicina no Brasil, comparando-se os anos de 1995 e 2012. Os dados apontam que houve um aumento de $662,47 \%$ no número total geral de vagas ofertadas durante o período. Nesse mesmo período houve um aumento muito menor no número de vagas de Medicina, que chegou a $117,42 \%$. Enquanto que o aumento do número total geral de inscrições no vestibular, durante os anos de 1995 e 2012, foi de 2.242,29\% para o curso de Medicina, o aumento chegou a $10.684,40 \%$.

A partir dos dados da Tabela, nota-se que no ano de 1995, o número de vagas ofertadas para o curso de Medicina (8.246) foi maior que o número de inscrições no vestibular (7.888), ou seja, 359 vagas ficaram ociosas para esse curso. No entanto, em 2012, o aumento no número de vagas para o curso de Medicina não atendeu à demanda, uma vez que houve um déficit de $4.744,15 \%$, ou seja, 832.743 vestibulandos não conseguiram ingressar no curso de Medicina em 2012, no Brasil.

Neste sentido, é possível constatar que a demanda pelo curso de Medicina no Brasil apresenta um aumento considerável quando se comparam os anos de 1995 e 2012. Desse modo, infere-se que a crescente procura por estudantes brasileiros em cursar Medicina na Bolívia e Paraguai deve-se ao fato de existirem poucas vagas para o curso no Brasil e também por que a maioria das vagas são ofertadas em instituições privadas $^{9}$, tornando-a inacessível para aqueles com menor poder aquisitivo.

De forma geral, a expansão da educação superior em escalas distintas entre Brasil, Paraguai e Bolívia tem desencadeado tensões no processo de revalidação de diplomas, já que o baixo índice de aprovações dentro do exame do Revalida aponta para uma possível divergência entre a Matriz Referencial para o curso de Medicina entre os

\footnotetext{
${ }^{9}$ Destaca-se que das 17.931 vagas oferecidas, em 2012, 42,46\% foram da rede pública (7.614) enquanto que as 10.317 vagas restantes foram disponibilizadas pela rede privada $(57,54 \%)$.
} 
países. E é com essa preocupação, segundo Sousa (2001), que o governo brasileiro tem investido em processos avaliativos da educação, tornando-a um importante instrumento de melhoria da qualidade de ensino.

\section{Considerações finais}

Diante do quadro aqui revelado, a partir dos estudos presentes na literatura educacional, pode-se inferir que a educação superior nas faixas de fronteira do Brasil, Paraguai e Bolívia vem ocorrendo à revelia das políticas supranacionais definidas e em processo de implementação, que não estão conseguindo induzir processos comuns e significativos para a construção de educação superior comum de qualidade nestes espaços. Diante disso, evidencia-se que existe um processo de mobilidade de estudantes brasileiros que buscam sua formação nestes espaços e que vem demandando a adoção de sistemas de avaliação e de regulação melhores e mais efetivos, especialmente considerando a dinâmica e sincronia dos tempos e espaços reais.

Esse movimento tem se constituído como um risco para a educação superior de qualidade uma vez que sinaliza para novas formas de comercialização da educação superior privada nos espaços de fronteira, o que demandaria, a exemplo do que aponta Kgnith (2006), a necessidade de construção de guias e acordos que tratassem das implicações das questões comerciais na educação transfronteira.

Espera-se que o estudo contribua para o desvelamento de possíveis efeitos da privatização da educação superior nas regiões de fronteira com o Brasil, de forma a subsidiar a realização de novos e mais estudos sobre a educação superior nestes espaços, para que se encontrem alternativas de políticas que permitam o monitoramento da qualidade na educação superior para além dos sistemas de avaliação e regulação vigentes.

\section{HIGHER EDUCATION AND MOBILITY IN BORDER RANGES: SOME EFFECTS OF ONGOING POLICY}

ABSTRACT: The higher education became strategic element for accelerating the process of development and consolidation of economies in recent decades, promoting its expansion, especially in the private sphere. However, it hasn't been enough to absorb the demand, on the rise of some careers more attractive. This process has stimulated Brazilian students to seek higher education institutions in border countries, such as Paraguay and Bolivia, raising concerns about the quality and curriculum equivalence of these courses. The thematic studies are incipient, especially considering the effects of 
mobility in the curriculum of undergraduate courses in these spaces. The theme is justified, considering the trends and tensions about the globalization and internationalization of higher education, with a view to facilitate new studies about this movement, which appears increasingly. Adopted as methodology the documentary and bibliographical analysis. In addition, it is expected that the study will contribute to the unveiling of possible effects of the privatization of higher education in border regions with Brazil, in order to indicate the performance of studies, to present policy alternatives that allow quality monitoring in the higher education in addition to the systems and existing regulation.

KEYWORDS: Higher education. Assessment policies. Mobilit. Cross-border education.

\section{REFERÊNCIAS}

\section{AGENCIA BRASIL. Diplomas estrangeiros poderão ter revalidação simplificada}

[online]. 2013. Disponível em: <http://noticias.bol.uol.com.br/ultimasnoticias/educacao/2014/06/03/diplomas-estrangeiros-poderao-ter-revalidacaosimplificada.htm>. Acesso em: 29 jun. 2014.

BRASIL. Instituto Nacional de Estudos e Pesquisas Educacionais Anísio Teixeira. Sinopses estatísticas da educação superior - graduação 1995/2012. Brasília: INEP, 1995. Disponível em: < http://portal.inep.gov.br/superior-censosuperior-sinopse>. Acesso em: 29 mar. 2015.

. Ministério da Educação. Acreditação de cursos no sistema ARCU-SUL.

Brasília: Secretaria da Educação, 2011a. Disponível em:

$<$ http://portal.mec.gov.br/index.php?option=com_content\&view=article\&id=13454:acre ditacao-de-cursos-no-sistema-arcu-sul\&catid=323:orgaos-vinculados $>$. Acesso em: 14 mar. 2011.

. Ministério da Educação. Decreto ${ }^{0}$. 5.518, de 23 de agosto de 2005 .

Promulga o acordo de admissão de títulos e graus universitários para o exercício de atividades acadêmicas nos estados partes do Mercosul. Brasília: Senado Federal, 2005. Disponível em: <http://www.planalto.gov.br/ccivil_03/_Ato20042006/2005/Decreto/D5518.htm>. Acesso em: 29 nov. 2013.

Ministério da Educação. Lei no 9.394, de 20 de dezembro de 1996. Lei de Diretrizes e Bases da Educação Nacional. Brasília: Secretaria da Educação, 1996. Disponível em: <http://www.planalto.gov.br/ccivil_03/LEIS/19394.htm>. Acesso em: 29 nov. 2013.

Ministério da Educação. Ministério da Saúde. Portaria Interministerial $\mathbf{n}^{\mathbf{0}}$ 278 de 17 de março de 2011. Institui o Exame Nacional de Revalidação de Diplomas Médicos expedidos por universidades estrangeiras (Revalida). Brasília: Secretaria de Educação, 2011b. Disponível em:

$<$ http://www.in.gov.br/imprensa/visualiza/index.jsp?jornal=1\&pagina=12\&data=18/03/ 2011>. Acesso em: 29 nov. 2013. 
. Ministério da Educação. Resolução CNE/CES no 8, de 04 de outubro de

2007. Altera o Art. $4^{\circ}$ e revoga o art. 10 da Resolução CNE/CES no 1/2002, que estabelece normas para a revalidação de diplomas de graduação expedidos por estabelecimentos estrangeiros de ensino superior. Diário Oficial da União, Brasília, 5 out. 2007. Disponível em:

<http://portal.mec.gov.br/cne/arquivos/pdf/2007/rces008_07.pdf >. Acesso em 29 nov. 2013.

Ministério da Educação. Selos de qualidade para cursos do Mercosul.

Brasília: MEC, 2009. Disponível em:

$<$ http://portal.mec.gov.br/index.php?option=com_content $\&$ view $=$ article $\&$ id $=8009 \&$ cati $\mathrm{d}=212 \&$ Itemid=86 > . Acesso em: 25 abr. 2009.

CARNEIRO, B. P. B.; NOVAES, I. L. Regulação do ensino superior no contexto da contemporaneidade. In: NASCIMENTO, A. D.; HETKOWSKI, T. M. (Org). Educação e contemporaneidade: pesquisas científicas e tecnológicas. Salvador: EDUFBA, 2009.

CASTRO, A. A.; NETO, A. C. O ensino superior: a mobilidade estudantil como estratégia de internacionalização na América Latina. Revista Lusófona de Educação, Lisboa, v.21, n.21, p.69-96, 2012.

CATANI, A. M.; OLIVEIRA, J. F. A educação superior. In: OLIVEIRA, R. P.; ADRIÃO, T. (Org.). Organização do ensino no Brasil: níveis e modalidades na Constituição Federal e na LDB. São Paulo: Xamã, 2002.

CONCEIÇÃO, J. C. A política de revalidação de títulos de graduação no Brasil: uma análise sobre a fronteira Brasil-Paraguai-Bolívia. In: $5^{\circ}$ SEMINÁRIO NACIONAL ESTADO E POLÍTICAS SOCIAIS, 2011. Anais... Cascavel: Unioeste 2011.

A expansão da educação superior e os efeitos no processo de revalidação de títulos de graduação em Mato Grosso do Sul. 2013. 156 f. Dissertação (Mestrado em Educação), Universidade Federal da Grande Dourados, Dourados, 2013.

; REAL, G. C. M. Indicadores de qualidade na avaliação na educação superior: congruências e incongruências das políticas brasileira e paraguaia. In: $3^{\circ}$ ENCONTRO DE INICIAÇÃO CIENTÍFICA, $3^{\circ}$ ENCONTRO DE EXTENSÃO, $2^{\circ}$ ENCONTRO DE PÓS-GRADUAÇÃO. Anais... Dourados: UFGD, 2009. p.1-14.

DIAS SOBRINHO, J. Educação superior sem fronteiras cenários da globalização: bem público, bem público global, comércio transnacional? Avaliação, Campinas, v.8, n.3, p.9-29, dez. 2003.

DOURADO, L. F.; OLIVEIRA, J. F.; CATANI, A. M. Transformações recentes e debates atuais no campo da educação superior no Brasil. In: Políticas e gestão da educação superior. São Paulo: Xamã, 2003. p.17-30.

ERICHSEN, H. Tendências europeias na graduação e na garantia da qualidade. Sociologias, Porto Alegre, n.17, p.22-49, jan./jun. 2007.

FERREIRA, S.; OLIVEIRA, J. F. As reformas da educação superior no Brasil e na União Europeia e os novos papéis das universidades públicas. Nuances, Presidente Prudente, v.17, p.51-68, 2010. 
GOMES, A. M.; MORAES, K. N. A expansão da educação superior no Brasil contemporâneo: questões para o debate. In: 32a Reunião Anual da ANPEd, CaxambuMG, 2009. Caxambu: ANPEd, 2009.

HORTALE, V. A.; MORA, J. G. Tendências das reformas da educação superior na Europa no contexto do processo de Bolonha. Educação \& Sociedade, Campinas, v.25, n.88, p.937-960, out. 2004.

KNIGHT, J. Higher education crossing borders: guide implications of the General Agreement on Trade in Services (GATS) for cross-border education. Paris: UNESCO, 2006.

.Un modelo de internacionalización: respuesta a nuevas realidades y retos. In: WIT, H. et al. (Ed). Educación superior em América Latina: la dimensión internacional. Tradução de J. Villamizar Herrera. Colômbia: Mayol Ediciones, 2005. p.1-38.

LAMARRA, N. F. Hacia la convergência de los sistemas de educación superior en América Latina. Revista Ibero-Americana de Educación, Madri, n.35, may./ago. 2004.

MERCOSUL. $1^{\text {a }}$ Reunião de Ministros da educação dos países-membros do MERCOSUL. Brasília, 1991. Disponível em:

<http://www2.mre.gov.br/unir/webunir/bila/06/2mercosu/merco09.htm>. Acesso em: 26 nov. 2013.

OLIVEIRA, R. P. Estado e política educacional no Brasil: desafios do século XXI. 2006. 106 f. Tese (Livre-Docência) - Faculdade de Educação, Universidade de São Paulo, São Paulo, 2006.

. A transformação da educação em mercadoria no Brasil. Educação \& Sociedade, Campinas, v.30, n.108, p.739-760, out. 2009.

OLIVEIRA, V. L.P. O PMM e a educação superior: globalização, política supranacional e medidas institucionais. 2014. Dissertação (Mestrado em Educação), Universidade Federal da Grande Dourados, 2014.

PEREIRA, E. M. A. O processo de Bolonha e formação do espaço europeu de educação superior-EEES: 10 anos da reforma universitária europeia. In: ; ALMEIDA, M. L. P. (Org.). Reforma universitária e a construção do espaço europeu de educação superior. Campinas: Mercado das Letras, 2011. p.7-27. v.1.

REAL, G. C. M. A avaliação da educação superior na fronteira Brasil - Paraguai: considerações sobre a construção de um espaço comum. In: $\mathbf{3 3}^{\mathbf{a}}$ Reunião Anual da Anped, Caxambu-MG, 2010. Caxambu: ANPEd, 2010.

. Impactos da expansão da educação superior na mobilidade estudantil: o eixo Brasil - Paraguai. In: 32 ${ }^{\mathbf{a}}$ Reunião Anual da ANPEd, Caxambu-MG, 2009. Caxambu: ANPEd, 2009.

Transformações recentes na educação superior na fronteira entre Brasil e Paraguai: os anos 2000. In: LIMA, P. G.; FURTADO, A. C. (Org.) Educação 
Brasileira: interfaces e solicitações recorrentes. Dourados: Ed. da UFGD, 2011. p.117140.

ROBERTSON, S. L. O processo de Bolonha da Europa torna-se global: modelo, mercado, mobilidade força intelectual ou estratégia para construção do Estado? Revista Brasileira de Educação, [S.1.], v.14 n.42, p.407-600, set./dez. 2009.

SCOTT, P. Pesquisa e contextos socioculturais no ensino de antropologia para cursos de graduação em saúde. In: 26a REUNIÃO BRASILEIRA DE ANTROPOLOGIA, 2008, Porto Seguro. Anais... Porto Seguro: RBA, 2008.

SGUISSARDI, V. Modelo de expansão da educação superior no Brasil: predomínio privado/mercantil e desafios para a regulação e a formação universitária. Educação \& Sociedade, Campinas, v.29, n.105, p.991-1022, 2008.

SOUSA, S. Z. L. Avaliação e políticas educacionais: iniciativas em curso no Brasil. In: HIDALGO, A. M.; SILVA, I. L. F. (Org.). Educação e estado: as mudanças nos sistemas de ensino no Brasil e Paraná na década de 90. Londrina: Ed. da UEL, 2001. p.69-98.

SOUZA, P. R. A revolução gerenciada: educação no Brasil, 1995-2002. São Paulo: Prentice Hall, 2005.

UNESCO. Institute for statistic data centre 2009 [online]. 2009. Disponível em: $<$ http://stats.uis.unesco.org/unesco/TableViewer/document.aspx?ReportId=136\&IF_Lan guage=eng\&BR_Topic=0>. Acesso em: 29 mai. 2014.

Institute for statistic data centre 2011 [online]. 2011. Disponível em:

<http://stats.uis.unesco.org/unesco/TableViewer/document.aspx?ReportId=136\&IF_Lan guage $=$ eng $\& B R \_$Topic $=0>$. Acesso em: 29 mai. 2014.

VARGUESE, N. V. Globalization of higher education and cross-border student mobility. Paris: UNESCO, 2008. 